\title{
Application in Process Industry of the Solid Particles Displacement on a Flat Oscillating Surface
}

\author{
EMILIAN-FLORIN MOSNEGUTU' ${ }^{1}$, VALENTIN NEDEFF ${ }^{1,2}$, NARCIS BARSAN $^{1}$, \\ ION SANDU ${ }^{3,4}$, MIRELA PANAINTE-LEHADUS ${ }^{1 *}$, DANA CHITIMUS ${ }^{1 *}$, \\ IOAN GABRIEL SANDU ${ }^{5,6 *}$, OVIDIU BONTAS ${ }^{7}$, DRAGOS-IOAN RUSU ${ }^{1}$, \\ GHEORGHE TOPAN ${ }^{8}$ \\ ${ }^{1}$ Vasile Alecsandri University of Bacau, Faculty of Engineering, 157 Calea Marasesti, 600115 Bacau, Romania \\ ${ }^{2}$ Gheorghe Ionescu Sisesti, Academy of Agricultural and Forestry Sciences Bucharest, 61 Marasti, 011464, Bucharest, \\ Romania \\ ${ }^{3}$ Alexandru Ioan Cuza University, ARHEOINVEST Interdisciplinary Platform, 22 Carol I Blvd, 700506, Iasi, Romania \\ ${ }^{4}$ National Institute for Research and Development in Environmental Protection, 294 Splaiul Independentei, 060031 \\ Bucharest, Romania \\ ${ }^{5}$ Gheorghe Asachi Technical University of Iasi, Materials Science and Engineering Faculty, 53A D. Mangeron Blvd., \\ 700050, Iasi, Romania \\ ${ }^{6}$ Romanian Inventors Forum, 3 Sf. Petru Movila Str., Bloc L11, III/3, 700089, Iasi, Romania \\ ${ }^{7}$ George Bacovia University of Bacau, 96 Pictor Theodor Aman Str., 600164, Bacau, Romania \\ ${ }^{8}$ University of Agricultural Sciences and Veterinary Medicine Cluj-Napoca, 3-5 Calea Manastur, 400372, Cluj-Napoca, \\ Romania
}

\begin{abstract}
In this paper we present a series of obtained results from the analysis of the behavior of a solid particle on a flat oscillating surface, a process that is found in separation operations of a heterogeneous mixture of solid particles. In this study, the inclination angle of the flat surface (7 or 10 degrees) and the eccentric device speed (91, 244 and $405 \mathrm{rpm})$ were varied. The results are extracted from video analysis using two commercial video cameras (Sony DCR-SR 36) with a recording speed of 25 frames per second, using the SynthEyes and Mathcad processing software. The obtained results from the analysis helped us to extract data showing the movement on the three axes $O X, O Y$ and OZ, average travel distance, average moving time of the solid particle on working surface and average velocity of the solid particle displacement.
\end{abstract}

Keywords: oscillating surface, inclination angle, solid particle, eccentric device speed

\section{Introduction}

The researches applied in process industries are very complex and refers to many aspects, from the particle size reduction, heterogeneous mixtures separation and up to energy consumption and processes optimizing [1-3].

Within the processing industry there are numerous ways to achieve the separation of components of a heterogeneous mix into distinct fractions. One of the oldest but also the most used method of separation is the separation according to size, method taking into account the three dimensional elements of a solid body: length, width and thickness [4]. This method is can be found in the facilities used in different processing industries, but also in analysis laboratories for solid granular products [5, $6]$.

This separation method is influenced by a series of factors with regard to the characteristics of the mix undergoing the separation process, as well as to the type of equipment carrying on this process, its operating mode and functional features [7-9].

Being aware of the travelling mode of solid particle on flat surface is the key element helping to optimize the mechanical separation process of a heterogeneous mix of solid particles $[10,11]$.

*email: mirelap@ub.ro,dana.chitimus@ub.ro, gisandu@yahoo.com 
The behavior of a solid particle on a flat oscillating surface, due to its complexity, is studied theoretically, by using different types of software to achieve the simulation of this process [9-12] or using different mathematical methods $[4,13,14]$, as well as practically, by making experimental determinations for different working conditions or for different facilities [12-14].

This article proposes to study the behaviour of a single solid particle on an oscillating surface. The experimental determinations took place on a laboratory stand, and a video camera has been uses to observe the behaviour of the solid particles.

\section{Materials and methods}

In order to identify the behaviour of a single solid particle on an oscillating surface, we used a laboratory stand having a blind sieve as working surface. The laboratory stand can vary the inclination angle of the working surface (Figure 1) [15-17].

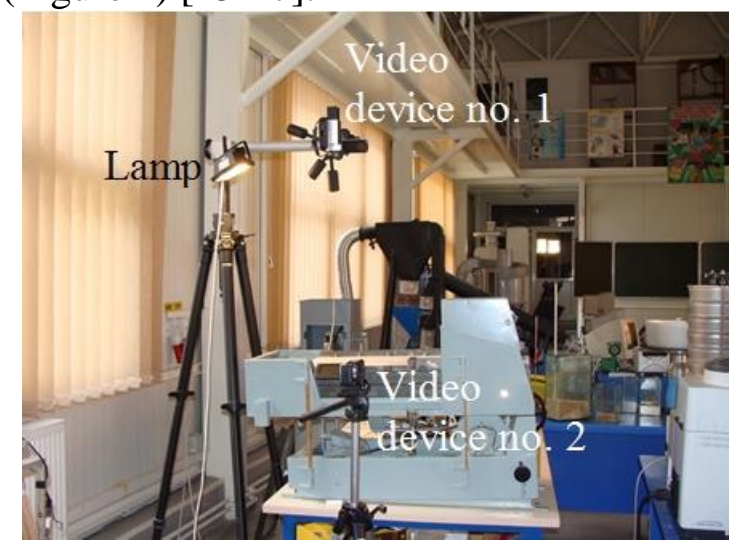

Figure 1. Laboratory stand and positioning of the two video cameras [15-18]

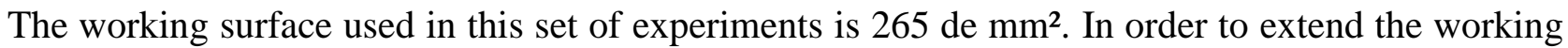
parameters, we also used a rotation speed variator, thus modifying the rotation speed of the crank gear generating the oscillatory movement of the sieve block.

The behaviour of the solid particle was monitored with two Sony commercial video cameras with a recording speed of 25 frames/s. These cameras have been placed in two perpendicular planes xOy and $\mathrm{xOz}$ (Figure 2) [15-18].

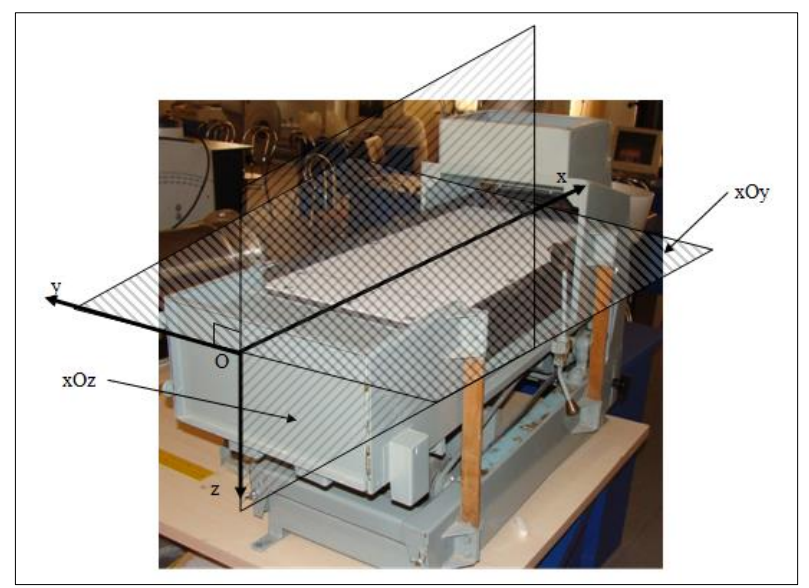

Figure 2. The working surfaces monitored by the two cameras [15-18]

The position of the two cameras aims to generate a three-dimensional trajectory of the solid particle on the oscillating surface. This can be obtained by combining the two final footages as they have the Ox axis in common. 
The material used for this study, i.e. the material moved on the oscillating surface, was real soy particles. A specific feature of these particles is the almost spherical shape (Figure 3) [18]. This viewing was made possible through the Excel Tri-plot v1.4.2.xls file [19, 20] by using the dimensional features of the solid particle: length, width and thickness [18].

For a more conclusive analysis of the behaviour of a solid particle on an oscillating surface, a set of experiments have been carried out in which varied series of work parameters of the stand operation mode (Figure 4).

For the experimental determinations we followed the working methodology showed in Figure 5.

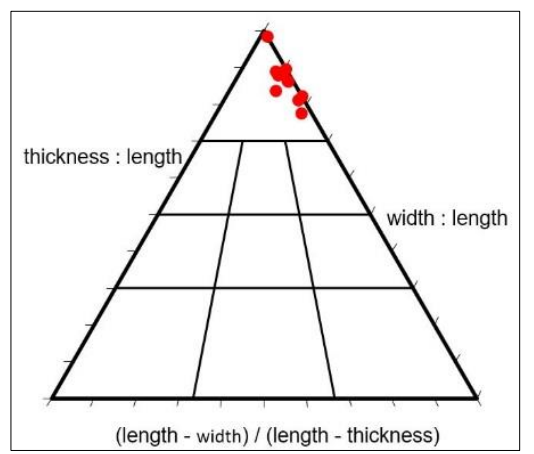

Figure 3. Graphical representation of the soy particles shape $[18,20]$

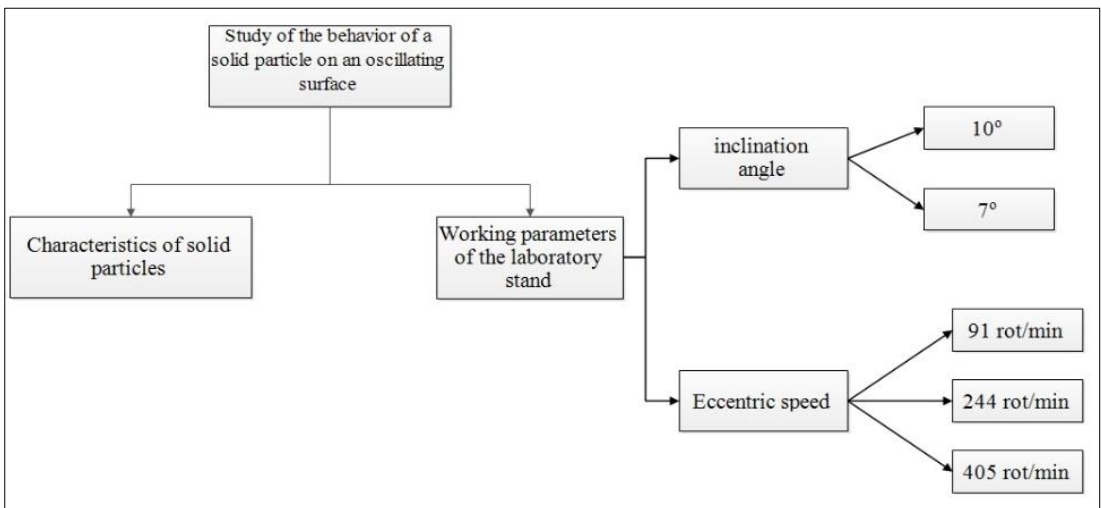

Figure 4. Working parameters

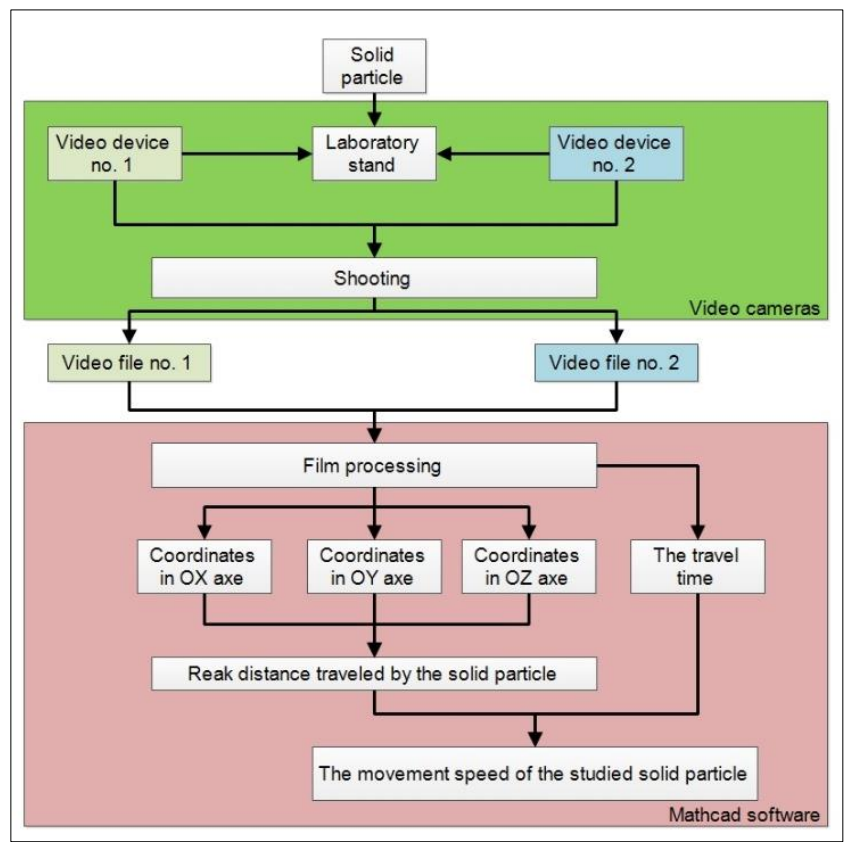

Figure 5. Working methodology [18] 
For the processing the data obtained by the two video cameras, we followed the diagram in Figure 6 , by using the following software:

- To extract the date from video files we used SynthEyes software, thus obtaining a *.txt file with the data required by the analysis.

- To process the data, to identify the analyzed parameters, to achieve the conversion and to determine the different characteristics, we used Mathcad software.

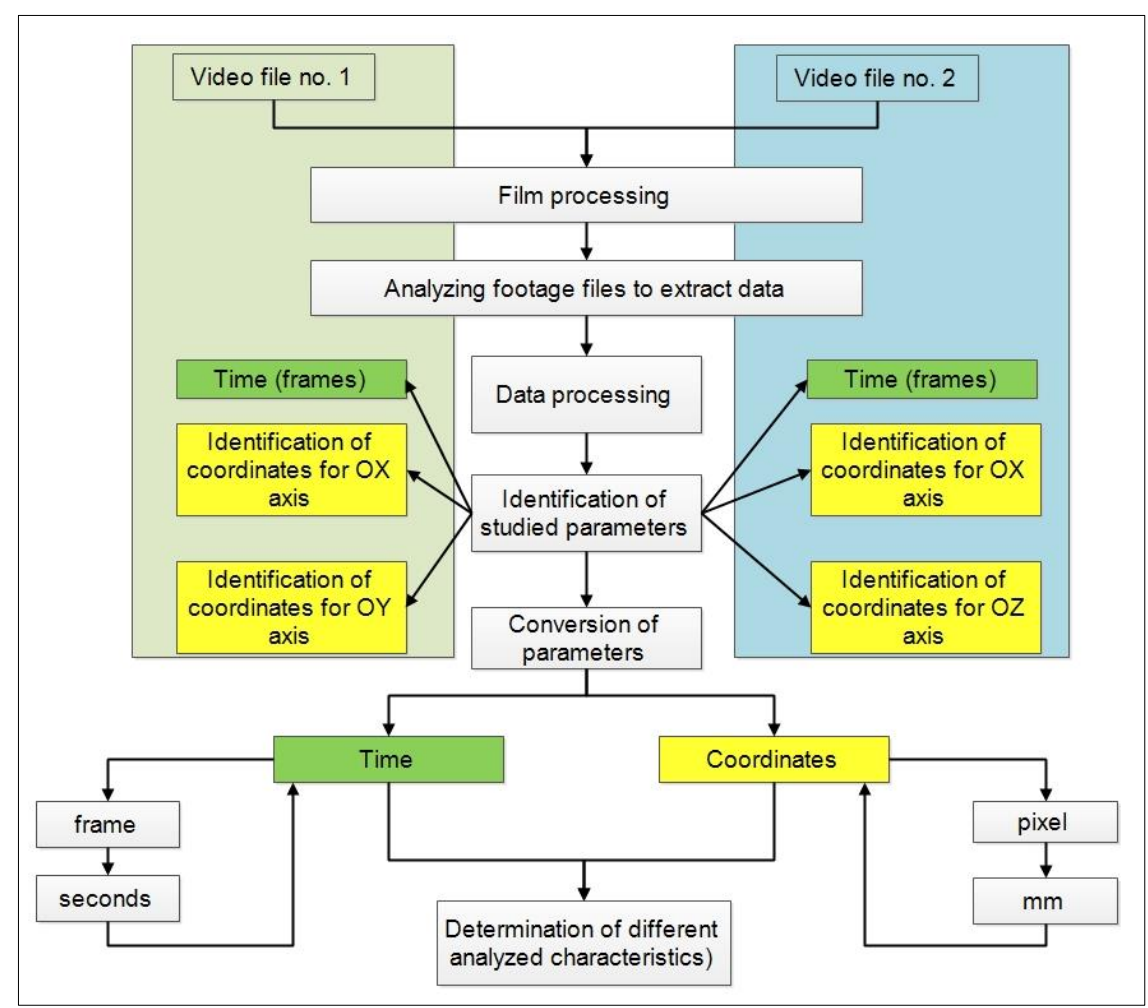

Figure 6. Data processing diagram

\section{Results and discussions}

Following the experimental determinations, the obtained results have been analyzed and a series of graphical representations have been drawn in order to view the influence exerted by:

- variation of the inclination angle of the working surface.

- variation of rotation speed of the eccentric device which gives the oscillation movement to the working surface.

The obtained parameters took into consideration the distance of displacement by the solid particle on the working surface, regardless of its direction of movement. axis.

Figure 7 shows the average values of the distances travelled by the solid particle on each individual

For the Ox axis we notice that the average value of the distance travelled by the solid particle on the $10^{\circ}$ inclination oscillating surface is higher than the average value of the distance travelled by the solid particle on the $7^{\circ}$ inclination oscillating surface. It was also found that at the $7^{\circ}$ inclination of the working surface, the distance travelled by the solid particle increases as the rotation speed of the eccentric device increases from $0.276 \mathrm{~m}$ to $0.278 \mathrm{~m}$, while at $10^{\circ}$ inclination it was found a decrease of the value from $0.281 \mathrm{~m}$ to $0.278 \mathrm{~m}$ followed by an increment up to $0.28 \mathrm{~m}$. 


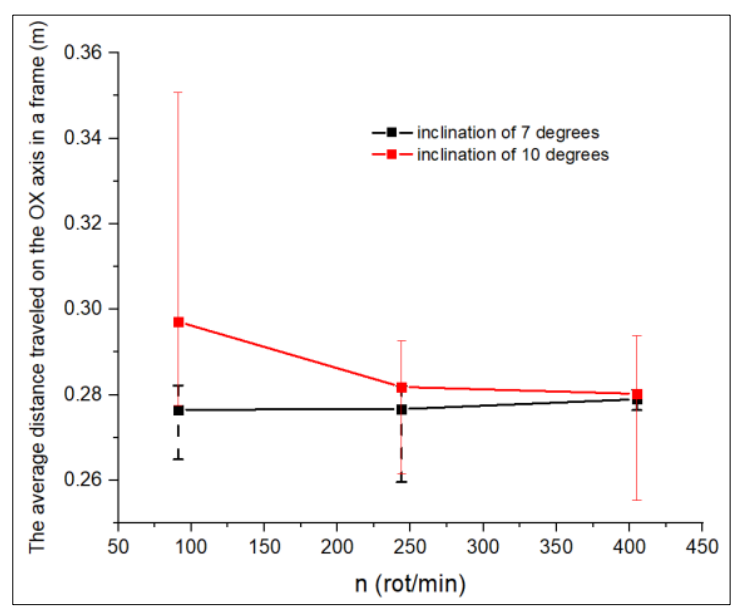

a

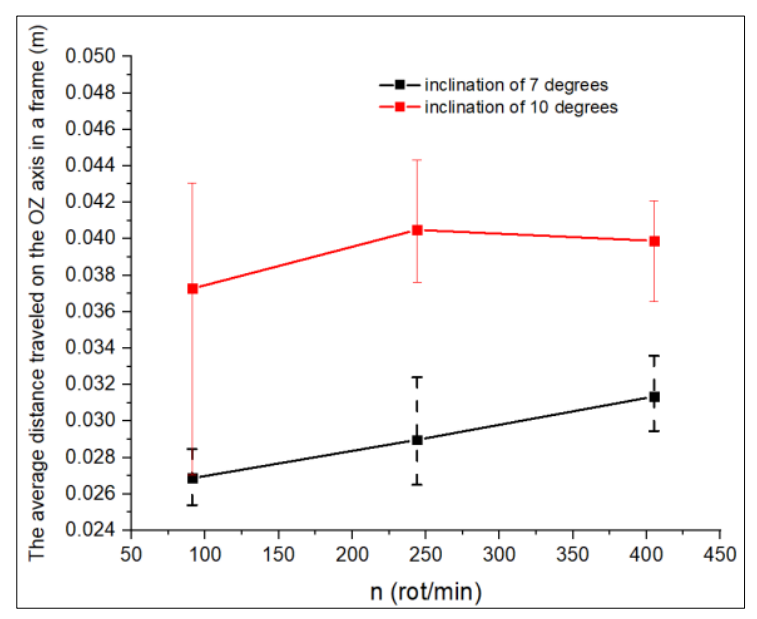

$\mathrm{c}$

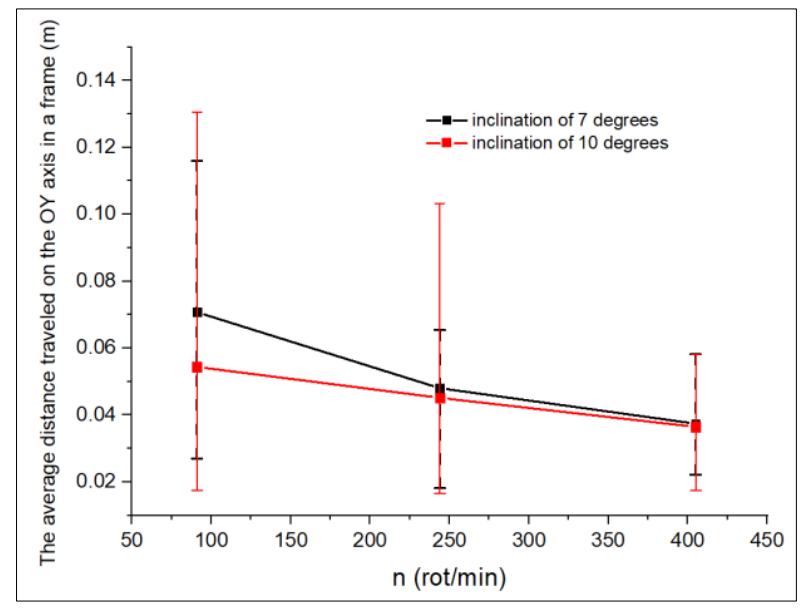

b

Figure 7. Variation of the average distance travelled by the solid particle on the oscillating surface according to the variation of the inclination angle of the working surface and the variation of the eccentric speed (rot/min):

a) OX axis; b) OY axis; c) $\mathrm{OZ}$ axis

For the Oy axis it was found that at $91 \mathrm{rot} / \mathrm{min}$ the difference between the two average values of the distance travelled by the solid particle is $0.02 \mathrm{~m}$. We must consider the fact that the values of the average distance corresponding to the $7^{\circ}$ inclination are higher than the values obtained for the $10 \mathrm{o}$ inclination. The difference between the values decreases with the increase of the value of eccentric rotation speed, reaching the value of $0.001 \mathrm{~m}$ at the speed of $405 \mathrm{rot} / \mathrm{min}$. Regardless of the value of the inclination angle of the working surface, the distance travelled by the solid particle decreases with the increase of the eccentric speed.

For the $\mathrm{Oz}$ axis, the highest average values of the travelling correspond to the $10 \mathrm{o}$ inclination surface. From the analysis of the graphical representation, it was found that the value of this parameter increases directly proportional to the increase of the value of the eccentric speed for the two values of the inclination angle of the working surface.

A general feature of the variation of the solid particle travelling on the oscillating surface is represented by the fact that the highest values are obtained for the travelling on the Ox axis, followed by the travelling on $\mathrm{Oy}$, and the lowest value is obtained for the travelling on the $\mathrm{Oz}$ axis.

Following the analysis of the variation of the average travelled distance of the solid particle on the oscillating surface (Figure 8) it was found that:

- For the eccentric rotation speed of $91 \mathrm{rot} / \mathrm{min}$., the highest values of the distance travelled is obtained for the $10 \mathrm{o}$ angle, i.e. $0.96 \mathrm{~m}$, and for the $7^{\circ}$ angle is 0.95 .

- As we increased the speed up to $244 \mathrm{rot} / \mathrm{min}$, we found that the value of the distance travelled on the working surface, for the $10^{\circ}$ angle, decreased by $0.013 \mathrm{~m}$, and for the $7^{\circ}$ angle decreased by 0.059 m. 


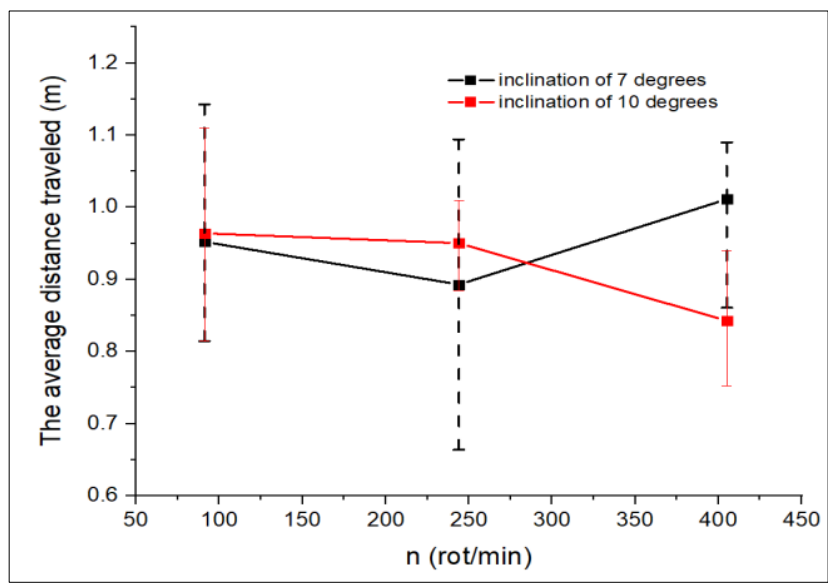

Figure 8. Variation of average distance travelled of the solid particle on the oscillating surface according to the variation of the inclination angle of the working surface and the variation of the eccentric speed

For the last value of the speed ( $405 \mathrm{rot} / \mathrm{min})$ it was found that for the $10^{\circ}$ angle the value of the average distance travelled by the particle decreases by $0.1 \mathrm{~m}$ compared to the previous value, and for the $7^{\circ}$ inclination angle the value of the average distance travelled by the particle increases by $0.118 \mathrm{~m}$ compared to the previous value.

After analyzing the variation of the time needed by the solid particle to travel the $265 \mathrm{~mm}$ (Figure 9) it was found that:

- The highest values are obtained for the $7^{\circ}$ inclination angle of the working surface.

- For the value of $91 \mathrm{rot} / \mathrm{min}$ it was obtained, for a $10^{\circ}$ inclination angle, an average time in which the solid particle travels the monitored distance of $0.88 \mathrm{~s}$, and for the $7^{\circ}$ inclination angle the value is $1.11 \mathrm{~s}$.

- For the $244 \mathrm{rot} / \mathrm{min}$ speed it was found that, regardless of the value of inclination angle of the working surface, the average time in which the particle travelled the $265 \mathrm{~mm}$ decreased by $0.08 \mathrm{~s}$.

- For a $405 \mathrm{rot} / \mathrm{min}$ eccentric speed it was found that for the $7^{\circ}$ inclination angle the time in which the solid particle travels the monitored distance increased by $0.112 \mathrm{~s}$ compared to the previous value, and in the case of the $10^{\circ}$ inclination angle of the working surface the value of time decrease by $0.064 \mathrm{~s}$ compared to the previous value.

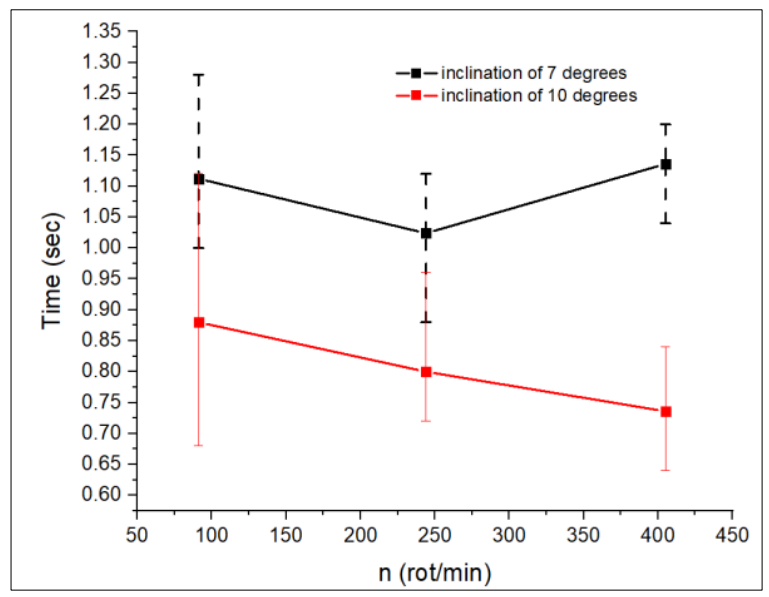

Figure 9. Variation of total travelling time of the solid particle on the oscillating surface according to the variation of the inclination angle of the working surface and the variation of the eccentric speed 
Knowing the average value of the distance travelled by the solid particle and the time required by the travelling, we can determine the average travelling value. Analyzing the graphical representation in Figure 10, the following conclusions can be drawn:

- The highest values of the average travelling speed of the solid particle are obtained in the case of the $10^{\circ}$ inclination angle of the working surface.

- In the case of a $7^{\circ}$ inclination angle working surface, it is found that the value of the average speed increases directly proportional to the increase of the eccentric speed: from $0.88 \mathrm{~m} / \mathrm{s}$ at $91 \mathrm{rot} / \mathrm{min}$ reaches $0.92 \mathrm{~m} / \mathrm{s}$ for $405 \mathrm{rot} / \mathrm{min}$.

- The shape of the variation of the average speed of the travelling of the solid particle on an oscillating surface is different in case of an inclination angle of the working surface of $10^{\circ}$. Initially, the value of the average speed increases from $1.18 \mathrm{~m} / \mathrm{s}$ to $1.26 \mathrm{~m} / \mathrm{s}$ corresponding to the interval 91 $244 \mathrm{rot} / \mathrm{min}$ for the eccentric speed. For the last value of the eccentric speed we found a decrease of the average travelling speed, this reaching the value of $1.21 \mathrm{~m} / \mathrm{s}$.

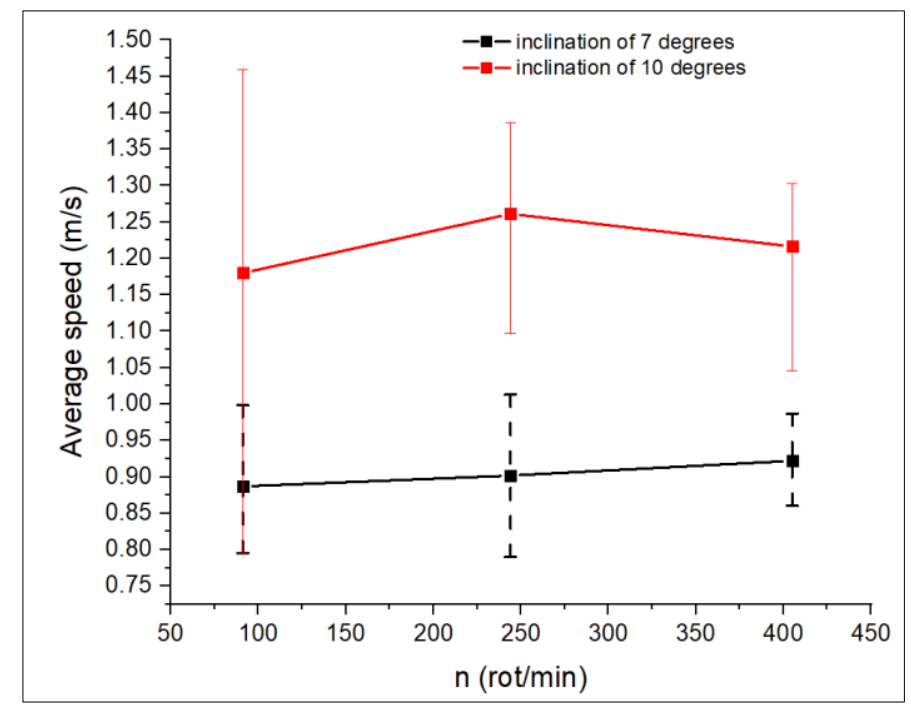

Figure 10. Variation of average travelling speed of the solid particle on the oscillating surface according

to the variation of the inclination angle of the working surface and the variation of the eccentric speed

\section{Conclusions}

After the analysis of the experimental results, the following conclusions are to be drawn:

a) For the travelling on the $\mathrm{OX}$ axis: The inclination angle of the working surface plays an important part, but this decreases with the increase of the eccentric speed.

b) For the travelling on the OY axis: The values obtained do not represent a considerable difference, regardless of the inclination angle and the eccentric speed, as we observed a general decreasing tendency.

c) For the travelling on the $\mathrm{OZ}$ axis:

- We observed a considerable difference between the values obtained at the $7^{\circ}$ inclination angle, where the lowest values have been obtained, and the $10^{\circ}$ angle, where we obtained the highest values.

- The eccentric speed sets an increasing trend to the obtained values, regardless of the inclination angle of the working surface.

d) For the average travelling distance: Initially, from $91 \mathrm{rot} / \mathrm{min}$ to $244 \mathrm{rot} / \mathrm{min}$ we observe a decrease of this parameter, regardless of the inclination angle. At $405 \mathrm{rot} / \mathrm{min}$ we observe that the value of the average travelling increased significantly for a $7^{\circ}$ angle, and for $10^{\circ}$ angle the increasing trend is kept, thus obtaining a significantly lower value. 
e) For the total average travelling time of the solid particle on the working surface:

- For the $7^{\circ}$ inclination angle it was initially found that the travelling time of the solid particle on the working surface decreases with the increase of the eccentric speed, followed by a significant increase of the value of this parameter for the last value of the speed.

- In the case of the $10^{\circ}$ angle it is found that the variation of the total travelling time of the solid particle on the working surface is inversely proportional to the variation of the working speed.

f) For the value of the average travelling speed of the solid particle:

- In the case of this parameter it was found that the inclination angle of the working surface plays an important part, this obtaining the highest values for the $10^{\circ}$ angle, and for the 7 degrees angle the lowest values.

- The variation of the eccentric speed directly influences the variation of the average travelling speed.

\section{References}

1. DASCALU, E.M., NEDEFF, V., CHITIMUS, A.D., BARSAN, N., Studies concerning the behavior of the suspended solids in the mixing process, Journal of Engineering Studies and Research, 21(4), 2015, 21-27.

2. PANAINTE, M., VALENTIN, N., CAROL, S., EMILIAN, M., Theoretical study regarding the possibility to determination the grinding energy to products with variable texture, Metalurgia International, 14(1), 2009, 62-67.

3. OLARU, C., NEDEFF, V., PANAINTE, M., Studies and research on the possibilities of cutting analysis of food materials with soft texture, Journal of Engineering Studies and Research, 17(1), 2011, $70-76$.

4. STANDISH, N., The kinetics of batch sieving, Powder Technology, 41(1), 1985, 57-67.

5. LIU, K.S., Some factors affecting sieving performance and efficiency, Powder Technology, 193(2), 2009, 208-213.

6. BORMASHENKO, E., LAUX, D., Oscillating/Vibrating Surfaces, Droplet Wetting and Evaporation: From Pure to Complex Fluids, Elsevier Publishinh House, 2015.

7. YUNG, H., Granular dynamics study of sieving, Theses 1132, New Jersey Institute of Technology, 1996.

8. ASS, R.L., JOHNSON, J.E., UNRUH, J.F., Correlation of lift and boundary-layer activity on an oscillating lifting surface, Aiaa Journal, 20(8), 1982, 1051-1056.

9. VOICU, G., STOICA, D., CONSTANTIN, G., CARP-CIOCARDIA, D.C., STEFAN, E.M., Influence of the granular mixture particles sizes and oscillation frequency on the separation process at the conical sieves with oscillating movement, Journal of Engineering Studies and Research, 20(4), 2014, 81-86.

10. TONG, X., LI, Z., QIU, Y., The research of particle sieving under a creative mode of vibration, Journal of Vibroengineering, 19(6), 2017, 4172-4184.

11. WU, X., LI, Z., XIA, H., TONG, X., Vibration parameter optimization of a linear vibrating banana screen using DEM 3D simulation, Journal of Engineering and Technological Sciences, 50(3), 2018, 346-363.

12. ELSKAMP, F., A framework for the derivation of dynamic process models for sieving, Dissertation, Technical University of Berlin, 2018.

13. ALEN, T., Powder Sampling and Particle Size Determination, Elsevier Science, 2003, 682.

14. CONSTANTIN, G., VOICU, G., IPATE, G., MUSUROI, G., STEFAN, E.M., GABRIELA, M., STOICA, D., Influence of motion type on granulometric distribution of grist obtained from some varieties of wheat and corn, 47 th Symposium, Opatija, Croatia, Actual Tasks on Agricultural Engineering, 2019, 409-417. 
15. BONTAS, O., NEDEFF, V., MOSNEGUTU, E.F., PANAINTE, M., IRIMIA, O.T., Behaviour of solid particles on a flat oscillating surface, Environmental Engineering and Management Journal, 12(1), 2013, 17-22.

16. MOSNEGUTU, E., NEDEFF, V., BONTAS, O., BARSAN, N., CHITIMUS, D., RUSU, D., Determination of kinematic indices corresponding to a solid particle on a flat oscillating surface, IOP Conference Series: Materials Science and Engineering, 147(1), 2016, art.no. 12151.

17. BONTAS, O., NEDEFF, V., MOSNEGUTU, E.F., PANAINTE, M., Study of factors influencing the solid particles on a flat inclined surface, Journal of Engineering Studies and Research, 18(1), 2012, 39-46.

18. BONTAS, O., Possibilities of optimizing the process of cleaning and sorting of the agricultural products granulometric by width and thickness, $\mathrm{PhD}$ Theses, Vasile Alecsandri University of Bacau, 2013.

19. GRAHAM, D.J., MIDGLEY, N.G., Graphical representation of particle shape using triangular diagrams: an Excel spreadsheet method, Earth Surface Processes and Landforms, 25, 2000, 1473 1477.

20.***Tri-plot: Ternary diagram plotting software. Available online: https://www.lboro.ac.uk/ microsites/research/phys-geog/tri-plot/index.html (accessed on 10.02.2020)

Manuscript received: 13.03 .2020 